\title{
Os processos psíquicos no interior dos grupos de trabalho: para além de Bion e Pichon-Rivière*
}

\author{
Gilles Amado ${ }^{1}$ \\ Escola de Altos Estudos Comerciais (Paris, França)
}

\begin{abstract}
Este artigo visa explorar os processos psíquicos no interior dos grupos de trabalho. Partindo das pesquisas pioneiras do psicanalista inglês Bion e do psicanalista argentino Pichon-Rivière, o autor mostra que as ansiedades subjacentes à realização da tarefa, descritas por esses autores, não têm necessariamente um caráter geral, na medida em que elas foram observadas principalmente em grupos de formação e de terapia. Daí vem sua proposição de fenômenos inconscientes complementares, desde que a tarefa apresente uma dimensão operatória e que o grupo de trabalho esteja inserido em um contexto organizacional. $\mathrm{Na}$ última parte, são detalhadas as capacidades psicológicas individuais requeridas pelo trabalho em grupo e as perspectivas, em termos de formação e de intervenção, que sua abordagem implica.
\end{abstract}

Palavras-chave: Ansiedades, Hipóteses de base, Grupo de trabalho, Processos inconscientes, Tarefa, Atividade.

Les processus psychiques au sein des groupes de travail, au-delà de Bion et Pichon-Rivière

Cet article vise à explorer les processus psychiques au sein des groupes de travail. En partant des recherches pionnières du psychanalyste anglais Bion et du psychanalyste argentin Pichon-Rivière, l'auteur montre que les anxiétés sous-jacentes à la réalisation de la tâche décrites par ces auteurs n'ont pas nécessairement un caractère général dans la mesure où elles ont été observées principalement dans des groupes de formation et de thérapie. D'où sa proposition de phénomènes inconscients complémentaires dès lors que la tâche présente une dimension opératoire et que le groupe de travail est inséré dans un contexte organisationnel. Dans une dernière partie, l'auteur détaille les capacités psychologiques individuelles sollicitées par le travail en groupe et les perspectives, en termes de formation et d'intervention, que son approche implique.

Mots-clés: Anxiétés, Hypothèses de base, Groupe de travail, Processus inconscients, Tâche, Activité.

Psychic processes within work groups: beyond Bion and Pichon-Rivière

This article aims at exploring psychic processes within work groups. Starting from the pioneering research of the British psychoanalyst Bion and the Argentinean one Pichon-Rivière, the author shows that the anxieties which exists below the surface of the task realization described by these two authors can't be generalized as they have been mainly within training and therapy groups. Therefore his proposal of other and complementary unconscious phenomena when the task is an operational one and when the work group is part of an organization. In a last chapter, the author describes the individual psychological skills necessary to be able to contribute effectively to a group work and the possible consequences in terms of training and intervention.

Keywords: Anxieties, Basic assumptions, Work group, Unconscious processes, Task, Activity.

\section{Introdução}

$E^{s}$ ste artigo visa explorar os processos psíquicos no interior dos grupos de trabalho, além das teorias de Bion e de Pichon-Rivière. Referimo-nos a esses dois autores por duas razões principais. De um lado, porque eles figuram entre os raros psicanalistas que desenvolveram, a partir de grupos de formação e de terapia, uma teoria e uma prática suscetíveis de tornar clara segundo eles - a dinâmica de todos os grupos de trabalho. De outro lado, temos de constatar que, mais ou menos cinquenta anos depois de seus primeiros trabalhos, sua presença ainda é considerável, não só entre os clínicos grupais do mundo inteiro, mas também - graças às numerosas práticas de formação que dizem basear-se neles - entre trabalhadores sociais,

\footnotetext{
* Publicado originalmente em: Nouvelle Revue de Psychosociologie, 15 (1), 163-182, 2013. DOI: 10.3917/nrp.015.0163

1 Professor emérito de Psicossociologia na Escola de Altos Estudos Comerciais (HEC) da França. Membro do Laboratório GREGHEC-CNRS.
} 
professores, administradores e diversos outros formadores. Com efeito, enquanto o estudo dos grupos operativos de Pichon-Rivière e seus discípulos é divulgado, sobretudo na América Latina e América Central (Fabris, 2007; Tubert-Oklander \& Hernandez de Tubert, 2004), os seminários de "relações grupais" inspirados na teoria e na prática de Bion espalham-se além do mundo anglo-saxônico (França, Itália, Israel, Turquia, Holanda, Bulgária, Suécia etc.).

Ora, parece-nos que, se o incontestável mérito destes dois pesquisadores foi aprofundar o estudo dos fenômenos grupais inconscientes que ocorrem na realização da tarefa, é precisamente a natureza e a concepção dessa tarefa que nos levam a questionar a generalização dos fenômenos observados. Em outras palavras, as análises extraídas dos grupos de formação e de terapia não me parecem necessariamente levar em conta toda a complexa química dos grupos de trabalho, pois, a meu ver, seus dispositivos limitam o alcance das análises. É claro que os grupos de terapia e de formação produzem um trabalho, mas eles visam, antes de tudo, um desenvolvimento individual, mesmo quando dão lugar a um trabalho grupal. Ora, os grupos de trabalho que focalizo aqui são centrados principalmente numa produção coletiva "extracentrada".

É por isso que, após lembrar as posições de Bion e de Pichon-Rivière relativas à dinâmica inconsciente dos grupos - particularmente as ansiedades subjacentes à realização do trabalho - e propondo uma crítica a elas, tentarei completar a abordagem desses autores com minhas próprias observações relativas aos grupos de trabalho, buscando tirar daí algumas perspectivas nos campos da formação e da intervenção.

\section{Bion e as hipóteses de base}

Lembremo-nos rapidamente da concepção de grupo de Bion (1965). Segundo ele, em qualquer grupo coexistiriam dois níveis.

O nível da tarefa, que corresponde ao nível consciente, racional, articulado em torno de procedimentos e papéis (concebidos segundo princípios científicos e meios sofisticados) que favorecem a cooperação. Esse nível define uma "mentalidade de grupo de trabalho" que nunca poderia ser pura, pois está sempre permeada pelo nível da valência.

O nível da valência, também chamado "protomental", subjacente às atividades de trabalho, refere-se à esfera emocional e é organizado em torno de três "hipóteses de base" (basic assumptions, às vezes traduzidas como "postulados de base"), ligadas entre si e podendo manifestar-se de forma alternativa:

- a hipótese de base "dependência" significa que os membros do grupo se comportam como se quisessem ser protegidos pelo líder, suposto detentor do saber que os nutriria intelectual e afetivamente;

- a hipótese "luta-fuga" (fight-flight) significa que o grupo reage como se estivesse ameaçado por um perigo e devesse se defender dele. O líder ou um bode expiatório, interno ou externo, tornam-se então as presas provisórias e aí o evitamento das dificuldades aparece de forma clara;

- a hipótese de base "acasalamento" (pairing) caracteriza os laços que se formam entre dois participantes no interior do grupo, simbolizando a promessa de que os problemas atuais do grupo poderão ser resolvidos. A fórmula "esperança messiânica" é muitas vezes utilizada nesse caso.

Sob vários aspectos, essas hipóteses são consideradas obstáculos à realização da tarefa.

Lembremo-nos logo de uma ambiguidade na posição de Bion, diante das hipóteses de base. De um lado, ele afirma que qualquer uma delas está sempre subjacente ao nível da tarefa (considerada como racional). Mas, além disso, ele quer mostrar que "é só quando um grupo 
começa a agir segundo uma hipótese de base que as dificuldades surgem" e que ele, o grupo, é "muito mais suscetível de ser submergido pelas hipóteses de base quando não está estruturado" (Bion, 1965, p. 91). Mas aqui fica a pergunta: as hipóteses de base constituem o inevitável fundo comum de todos os grupos ou dependem do quadro no qual os grupos evoluem?

A fim de clarear essa questão, seria útil voltar ao contexto no qual nasceu a teoria de Bion, a certos elementos de sua história pessoal, ao objeto designado aos grupos que ele conduziu, enfim, ao dispositivo e à técnica que ele propôs.

Bion desenvolveu sua teoria durante a Segunda Guerra Mundial, trabalhando com grupos terapêuticos para tratar os neuróticos de guerra no hospital Northfield (Harrison, 2000), antes de conduzir psicoterapias de grupo na Clínica Tavistock, em Londres. Como oficial de um regimento de tanques, ele se distinguiu pela bravura e esta lhe valeu diversas condecorações, estranhamente vividas como "um grande fardo, na medida em que ele deveria, daí em diante, ser bravo, embora se sentisse interiormente covarde" (Pines, 2009, p. 9). Outra questão que teve consequências em sua prática ligava-se à sua surpreendente preocupação com a obediência dos soldados às ordens. De fato, a experiência da guerra teve um papel determinante em sua reflexão, a ponto de Manie Sher (1988, p. 130) ter escrito que ele concebeu o grupo como um "teatro de guerra, buscando identificar o perigo no interior do grupo e utilizando a guerra para pensar o grupo". Podemos acrescentar à metáfora da guerra uma outra, a da religião (esta estaria no cerne da hipótese de base "acasalamento"), as duas constituindo o solo fértil de uma espécie de cruzada para a emancipação dos homens, vistos finalmente não como sujeitos passivos, mas como seres capazes de refletir sobre suas experiências, de desenvolver um pensamento próprio, de elaborar, por si mesmos, decisões e julgamentos maduros (Sher, 1988, p. 134). Por isso, Bion pensava que, enquanto o grupo funcionava segundo as hipóteses de base "luta-fuga" e "acasalamento", os participantes agiam como adultos, o que não ocorria quando predominava a hipótese "dependência".

Finalmente, nota-se sua grande decepção diante das instituições, em parte em função do modo como sua primeira mulher foi (mal) tratada antes de sua morte repentina no hospital.

Os diferentes aspectos de sua experiência íntima talvez expliquem em parte o objeto central de seu trabalho, bem como o dispositivo que ele criou e a respeito do qual ele declarou: "nos grupos em que sou psiquiatra, cabe-me, em virtude de minha posição, o direito de estabelecer as regras de procedimento. E eu aproveito isso para não estabelecer nenhuma regra e não apresentar nenhuma ordem do dia". Diante dos soldados traumatizados pela guerra, Bion, contrariamente a Foulkes (que conduziu terapias de grupo no mesmo hospital), centrará seu trabalho essencialmente no grupo, aparentemente deixando de lado as neuroses individuais e enfatizando a neurose de grupo (Brown, 1985), entronizada como substituto do inimigo militar, convidando assim os participantes a explorar a patologia social (Hinshelwood, 2009). Manie Sher resume: "Bion trabalha constantemente com o paradoxo do grupo perturbado que trata de si mesmo" (p. 131). Sua atitude muitas vezes se assemelha àquela de um shaman. Segundo Eric Trist, que o conheceu bem de perto, seu trabalho estava centrado unicamente na transferência (Pines, 2009, p. 10) e no aqui e agora, como atesta a célebre injunção "sem lembrança nem desejo" (without memory or desire) que ele dirige a si mesmo (e que seria retomada por vários de seus discípulos) como responsável e como analista de grupo. Eis aí quem, por natureza, costumava desconcertar os participantes habituados a uma estrita hierarquia e a regras precisas. A frágil clareza dos objetivos perseguidos por ele se fazia sentir no interior do hospital militar de Northfield. Ali, na experiência de readaptação conduzia com Rickman, todos supunham que "o objetivo era ou reenviar os sujeitos ao campo de batalha ou, ao contrário, ajudar todos os preguiçosos a perseverar em sua conduta", como nota o próprio Bion (1965, p. 41).

O analista de grupo Dennis Brown (1985, pp. 79-80) assim resume, com severidade discutível, sua crítica a Bion: "Suas conclusões poderiam provir de condições que ele havia imposto, em particular por seu estilo caracterizado pela distância e pela provocação de 
frustrações, privilegiando aspectos malsãos, psicóticos e despersonalizados do funcionamento de um grupo", chegando mesmo a considerar suas hipóteses de base como pouco pertinentes para os grupos terapêuticos. Segundo ele, "trata-se de fenômenos correntes nas situações hostis a um diálogo livre e aberto", tais como podemos encontrar em agrupamentos de caráter rígido. Além disso, Bion fazia uma separação bastante clara entre o consciente e o inconsciente, o indivíduo e o grupo, uma vez que "em um grupo, os membros podem, em níveis diversos de consciência e de regressão, segundo suas necessidades e suas preocupações, argumentar racionalmente ante os acontecimentos" (Bion, 1965, p. 79).

Enfim, aproximando-me parcialmente de Brown e com base em minha experiência com grupos, ${ }^{2}$ parece-me que as hipóteses de base concebidas por Bion são, antes de tudo, solicitadas por seu dispositivo. É isso, aliás, que Rouchy (1986, p. 115) deixa entender quando declara: "A dinâmica dos processos descritos por Bion em suas dimensões grupais [...] não poderia ser compreendida independentemente do dispositivo instituído". Evidentemente, isso não tira seu valor heurístico, mas pode limitar o seu alcance. Com efeito, todo dispositivo opera um corte na realidade, permitindo-nos apreender uma parte dela e deixando necessariamente ocultos outros aspectos.

Como compreender, então, a gênese e o alcance do dispositivo inventado por Bion? Traumatizado, de alguma forma, por sua experiência da guerra e pelo exercício da autoridade hierárquica relacionada a um poder muitas vezes ilegítimo e recalcitrante ante os meandros patogênicos das organizações burocráticas, Bion se interessou inicialmente pela realização da tarefa ${ }^{3}$ no interior dos grupos e pelo "justo" investimento dos papéis por cada membro. Assim, curiosamente, criou um dispositivo no qual essas duas dimensões eram facilmente apreensíveis. Nem a instituição e nem os participantes podiam de fato ser aí encontrados, pois a proposta de Bion, embora baseada em uma intuição fecunda, estava insuficientemente elaborada - talvez bastante reativa em relação ao contexto. Recusando toda estrutura e toda autoridade aparente, em contraste com a estrutura militar com a qual seus pacientes eram confrontados e da qual ele era o guardião, ele adotou uma postura na qual a livre palavra, vivida também como um laissezfaire, ecoava interpretações grupais um pouco misteriosas, em parte ligadas às hipóteses de base. Quebrando expressamente toda a estrutura clássica, Bion requeria, assim, as ansiedades psicóticas paranoides e depressivas que seu interesse pela obra de Melanie Klein tinha despertado. Com efeito, ele declarava "chegarei mesmo a dizer que são estas últimas [as ansiedades primitivas ligadas às relações de objeto parcial] que estão na origem de todas as formas de comportamento de grupo" (Bion, 1965, p. 130). Com isso, ele tinha a hipótese de que sua análise permitiria, ao mesmo tempo, compreender melhor os fenômenos de grupo, aumentar a autonomia dos sujeitos e ajudá-los a curar-se. Nesse caso, é possível que o fenômeno psicossocial em jogo nos pareça mais próximo da profecia autorrealizadora (Rosenthal \& Jacobson, 1971) que de uma descoberta "científica" (à qual, em todo caso, Bion não aspirava verdadeiramente): afinal, o que há de mais normal que oscilar entre a dependência (em relação a um instituinte que não nos explica quase nada de seu projeto ou de seu dispositivo e a quem não dirigimos uma demanda específica), a luta-fuga (fruto de movimentos paranoides e depressivos, compreensíveis diante de uma determinada situação ${ }^{4}$ ) e o acasalamento (ou seja, a busca constante de uma saída frente a essa situação inconfortável)? Mesmo que Bion tenha inventado seu dispositivo antes de ter entrado em análise, ele o centrou na cura individual, provocando a regressão em grupo (criticada por Nitsun, 1996) e contando

2 Depois de ter participado de numerosos grupos de formação de orientação psicanalítica, há algumas décadas eu mesmo tenho conduzido grupos de terapia em um CMPP (centro médico-psico-pedagógico), além de grupos de formação, com vários analistas de grupo, na França, na Inglaterra e na Itália, junto a responsáveis por organizações. Tenho também conduzido grupos de análise de práticas em diversos meios profissionais.

3 Não nos esqueçamos de que Bion, antes de tudo, estava interessado não propriamente pelas relações de grupo, mas em ajudar os grupos a realizar sua tarefa. Ele desejava encorajar os homens a pensar no papel que eles tinham em relação a uma tarefa específica (Sher, 1988, p. 133).

4 Aliás, Bion se declara surpreso pelo fato de que, como líder do grupo, ele seja considerado como um inimigo a ser abatido... 
com a transferência numa situação à qual ela não se prestava forçosamente. Será que ele se deu conta disso a posteriori?

Em todo caso, ele viu que sua abordagem terapêutica não trazia necessariamente benefícios em relação ao "funcionamento" dos indivíduos na guerra ou no trabalho (Sher, 1988, p. 113). Foi por isso que Bion ficou particularmente surpreso com a grande repercussão de seu método fora do campo terapêutico. Tendo interrompido sua pesquisa sobre os grupos - e o próprio trabalho com grupos - um pouco mais de dois anos depois de os ter formulado, "foi deixada a outros a transformação dos métodos de Bion e o fato de os situar, antes de tudo, nas relações de trabalho" (Sher, 1988, p. 45).

Note-se que a extensão - se não a modificação - das ideias de Bion foi também encorajada por David Armstrong (1992), estigmatizando "a atrofia teórica e metodológica autoinfligida" pelos discípulos mal munidos de referências. Afinal, é preciso reconhecer que, a despeito de afirmações e de postulados discutíveis, Bion forneceu as "hipóteses" que acabaram se transformando, em todas as partes, em um credo.

Naturalmente, se centramos nossa reflexão nos grupos de trabalho (e não mais nos grupos terapêuticos), podemos reencontrar episódios nos quais as hipóteses de base podem ser observadas, sobretudo dependência e luta-fuga, assim como alguns fenômenos coletivos que delas se aproximam. Mas convém fazer algumas observações sobre isso. Em primeiro lugar, elas podem ser o produto de um comportamento voluntário ou inconsciente da pessoa central, que, assim, cria a dependência e a contradependência. Elas podem também não corresponder aos mecanismos de defesa inconscientes, mas a reações preconscientes, conscientes e/ou estratégicas da parte dos membros do grupo, que podem, assim, chegar a um acerto de contas. Uma breve imagem permite ilustrar esse ponto:

Dando um curso sobre as teorias de organização, fico surpreso com o peso de certas críticas vindas de vários estudantes e, em seguida, com seu rápido (excessivo?) silenciamento diante de minhas respostas. Conversando com alguns deles, na hora da pausa, eles me dão duas explicações sobre o acontecido: essas teorias lhes parecem um pouco abstratas; eles tomam a palavra apenas para "existir" e "provocam o professor só para dar mais vida à sala de aula". Essa atitude é, além disso, considerada como "pagamento", pois uma nota de participação deve ser dada a cada estudante.

A luta-fuga aparece nesse relato como um comportamento estratégico largamente calculado. Isabel Menzies-Lyth (2002) poderia considerar pertinente essa reação dos estudantes, tendo em vista o funcionamento institucional e o objetivo de cada membro no grupo - portanto, isso seria trabalho. No entanto, lembremo-nos de que a afirmação de Bion, em momentos distintos, de que todos os grupos funcionam segundo uma hipótese de base, não corresponde à observação dos grupos de trabalho em que a cooperação se realiza sem problemas mesmo quando estes são atravessados por ansiedades diversas. Nesse caso, a crítica recente de Dejours (2012) a Freud, no sentido de que este só se debruçou sobre dois grupos bastante específicos e fortemente hierarquizados - a Igreja e o Exército -, negligenciando assim a dimensão criativa das coletividades, tem um paralelo com a crítica que podemos fazer a Bion a respeito do alcance supostamente geral de sua teoria.

O psicanalista de grupo italiano Claudio Neri (2011, p. 36), bastante inspirado em Bion, parece concordar com essas observações sobre os grupos de trabalho, ao declarar:

[...] mesmo que a ideia de Bion sobre a existência de uma mentalidade de grupo de trabalho tenha tido menos sucesso que aquela relativa à mentalidade primitiva (hipóteses de base), creio que essas duas noções são inseparáveis. Penso também que o analista de grupo deve consagrar ao desenvolvimento do grupo de trabalho uma atenção ao menos igual, senão superior, àquela

5 Se acreditamos nos estudos de acompanhamento terapêutico de seu método (Malan et al.,1979), seu impacto parece ter sido pequeno, tendo seus pacientes declarado que suas experiências de terapia de grupo não os tinha particularmente ajudado. Para muitos, a experiência de Northfield foi considerada um fracasso. 
que ele consagra à análise dos fenômenos próprios da mentalidade primitiva. $\mathrm{O}$ pensamento do grupo, com efeito, é o fruto e a expressão do grupo de trabalho.

Como bem observaram French e Simpson (2010, p.1866), dando ênfase à necessária racionalidade do grupo de trabalho, Bion "eclipsou o papel dos fatores inconscientes e emocionais no funcionamento do grupo de trabalho, como se eles pertencessem apenas ao domínio das hipóteses de base".

\section{Grupos operativos e ansiedades psicóticas em Pichon-Rivière}

Entre os psicanalistas de grupo, Pichon-Rivière é dos raros que tentou contornar o obstáculo representado pela negligência com o trabalho, colocando a tarefa concreta e o aspecto criativo dos grupos no centro de sua análise e de seu dispositivo de formação.

Bastante inspirado em Kurt Lewin, George Mead, Henri Lefebre, Marx e Sartre, ao lado de Freud e Melanie Klein, ele concebe o sujeito como sendo ligado a um sistema de interrelações dialéticas, um sujeito que seria produto da interação entre o mundo interno (intrassistêmico) e o mundo externo (intersistêmico). O sujeito saudável seria então aquele que tem "uma relação dialética com o meio e não uma relação passiva, rígida e estereotipada" (Jaitin, 2002, p. 147). Partindo da psicanálise em direção à psicologia social, ele afirma que esta última, caso fique apenas no estudo das relações interpessoais, tornando-o "direcional e significativo", tenderá a se esclerosar e a perder seu sentido. Daí vem o fato de ele ter criado seu Esquema Conceitual Referencial Operativo $(\mathrm{ECRO}),{ }^{6}$ orientado para o aprendizado através da tarefa e do desenvolvimento de sua técnica dos grupos operativos, assunto nos quais nos deteremos agora.

Trata-se de uma técnica que Pichon-Rivière criou em 1946. Ele era então responsável pelo serviço para adolescentes do hospital neuropsiquiátrico para homens, em Buenos Aires, quando houve uma demissão (ou uma suspensão?) repentina do conjunto do pessoal da enfermagem. Isso o levou a transformar os pacientes de seu serviço em "operadores", através de um processo de formação em grupo, o que o ajudou a construir sua teoria dos grupos - bem como sua técnica, utilizada desde então não apenas para a formação de psicólogos, mas também para a formação de "líderes", para o trabalho de teatro (encenação e interpretação), por exemplo.

Para Pichon-Rivière, a tarefa do grupo - que pode ser a aprendizagem, o cuidar de pacientes, o diagnóstico das dificuldades de uma organização do trabalho, a criação publicitária etc. - supõe sempre duas ansiedades de base que perturbam a aprendizagem e a comunicação e são a base do que ele chama de "resistência à mudança". A primeira é "o medo da perda" das estruturas existentes (em relação com a ansiedade depressiva); a segunda é "o medo de ser atacado" (ansiedade paranoide) na nova situação de formação que produz insegurança. Encontramos aqui uma proximidade com Melanie Klein e Bion. O papel do "coordenador" consiste então em ajudar o grupo a pensar, "abordando o obstáculo epistemológico constituído pelas ansiedades de base" (Pichon-Rivière, 2004, p. 29), e a tarefa central seria elaborar essas duas ansiedades.

Somemos outro elemento importante do dispositivo dos grupos operativos: a maior heterogeneidade possível dos membros do grupo, passível de fazer crescer sua produtividade. Em relação a esse aspecto, quatro papéis são explorados mais especificamente:

6 Com relação ao ECRO, Jaitin (2002, p. 167) afirma: “o 'esquema' é também uma construção comum aos membros do grupo; o 'conceitual' designa o conjunto dos conceitos elaborados em grupo para tornar-se, em seguida, conceitos operacionais e funcionais; o 'referencial' remete ao 'esquema de referência' de cada sujeito, criado em função de seu pertencimento a outros grupos; o 'operacional' corresponde ao conjunto dos atos, tomados como meios necessários para se obter um resultado". 
- o porta-voz (Jaitin, 1994), também chamado "espião" ou "poeta-radar": é um membro do grupo que, em certo momento, "denuncia" o que se passa no grupo, as ansiedades que o atravessam, articulando assim seu fantasma inconsciente com a realidade que ele percebe. O porta-voz de Pichon-Rivière é próximo da função fórica descrita por Kaës (1993);

- o líder, depositário dos aspectos positivos do grupo;

- o bode-expiatório, receptáculo dos aspectos negativos ou ameaçadores do grupo;

- o sabotador, líder da resistência à mudança.

De novo, parece-nos que esses diversos elementos são o produto de um dispositivo estritamente analítico e de uma concepção bastante mecânica, ou mesmo normativa, dos processos psíquicos em curso nos grupos, mesmo que o foco em uma atividade profissional permita aos grupos de Pichon-Rivière serem mais criativos, limitando os riscos de descompensação presentes nos dispositivos menos operativos.

Tornemos mais precisas algumas de nossas críticas:

- os dois tipos de ansiedade repertoriadas por Pichon-Rivière, medo da perda e medo do ataque, são bastante ligados, a um só tempo, à heterogeneidade do grupo (que aumenta sua desorientação) e ao papel distante do coordenador, que só intervém em caso de bloqueio do "funcionamento" do grupo, arriscando-se a ficar só vigiando a emergência dessas ansiedades, como uma espécie de boia de salvação diante da complexidade e da incerteza;

- o porta-voz pode ser o enunciador (e não o denunciador) de fantasias grupais, mas ele não desempenha forçosamente esse papel. Até que haja prova em contrário, ele pode exprimir apenas sua fantasia pessoal, desvinculada da problemática grupal subjacente. $\mathrm{Na}$ ausência de verificação das ressonâncias psíquicas, a concepção desse papel é mecanicamente sistêmica;

- o líder pode ser escolhido por sua função de resistência, como mostrou Béjarano (1973), ou por sua caução às mais mortíferas pulsões, como a História, tristemente, nos ensinou;

- o bode expiatório e o sabotador devem ser vistos como produções grupais mais ou menos momentâneas e não como papéis "obrigatórios", pois isso implicaria o risco de cairmos numa abordagem estritamente comportamental e tipológica dos fenômenos de grupo;

- enfim, a insistência sobre a necessidade da heterogeneidade é discutida em função do objeto de trabalho. Mas, em que ela facilita uma melhor compreensão da dinâmica de tais grupos? Maior eficácia? Maior bem-estar na realização do trabalho?

Decerto tais críticas não levam em conta a extensa obra e a abordagem mais completa dos grupos, não apresentada aqui (Fabris, 2012), em especial a proposta dialética de PichonRivière entre o sujeito e seu ambiente, a pesquisa sistemática da infraestrutura inconsciente das ideologias nas interações internas do grupo, a análise sistemática das contradições. Tudo isso pode ser de grande interesse para a compreensão do funcionamento dos grupos de trabalho, mas sob a condição de que essa pesquisa não iniba as forças criadoras em germinação.

\section{Trabalho, atividade e grupo de trabalho}

Para compreender o funcionamento de um grupo de trabalho, não se pode abstrair seu contexto e o papel que este tem nos fenômenos observados. Essa observação foi formulada inúmeras vezes, em especial pelos críticos dos seminários de dinâmica de grupo. Lembremo-nos aqui das denúncias dos grupos "em roda livre", feitas por Elliott Jaques (1995); e da crítica aos grupos de evolução, feitas por André Lévy (1972) e pelos teóricos franceses da análise institucional (Lapassade, 1967). Quando não se levam em conta os elementos do contexto, corre-se enorme risco de uma psicologização do social, com interpretações essencialmente psicológicas dos fenômenos sociais e psicossociais. 
Estando sempre inscrito nas relações sociais, o trabalho é objeto de tensões, de debates e de conflitos, fruto de representações individuais e sociaias que se entrechocam. Além disso, o trabalho não é a "tarefa primária" (primary task), confusão que se dá muitas vezes a esse respeito. Com efeito, a tarefa primeira corresponde à prescrição, definida quase sempre pela hierarquia. $\mathrm{O}$ trabalho é a atividade realizada concretamente para se tentar realizar a prescrição (Amado \& Lhuilier, 2011) e essa tentativa exige a criatividade dos trabalhadores (em todos os níveis da organização), o que muitas vezes implica uma transgressão das regras e procedimentos. De fato, as melhores prescrições do mundo não podem antecipar os imprevistos, as falhas, as insuficiências que o real desvela e impõe (Clot, 2009; Dejours, 2009; Lhuilier, 2006a).

O grupo de trabalho sobre o qual nos interessamos aqui pode ser definido como um conjunto de pessoas reunidas em um ambiente específico em torno de uma tarefa e de um objetivo comum, cuja realização depende do recurso à inventividade e à ajuda mútua, bem como da dependência de uma autoridade voluntaria ou inconscientemente exercida e/ou consentida.

Em relação a esse último caso - a dependência a uma autoridade -, parece-nos que as hipóteses de base de Bion ou as ansiedades descritas por Pichon-Rivière (ou seu simulacro) podem aparecer como forma dominante. Nesse terreno, os comportamentos manipuladores por parte das figuras de autoridade são aqueles que podem suscitar as mais profundas ansiedades. Convém reconhecer que essas situações estão longe de ser excepcionais - queremos aqui abordar os processos e problemas mais comuns nos grupos de trabalho, o quanto eles são conduzidos (coletivamente ou por um responsável) de maneira "democrática" no sentido lewiniano do termo. Se, como diz Dominique Lhuilier (2006b, p. 226), o trabalho é a cena na qual aparecem, simultânea e dialeticamente, a relação consigo mesmo, com o outro e com o real, pode-se afirmar que os grupos de trabalho são lugares em que melhor se pode produzir: o reconhecimento de si, as relações férteis, a criatividade coletiva.

Cada uma dessas dimensões depende dos problemas em jogo e do contexto do grupo de trabalho, mas a resolução dos problemas e o desenrolar dos projetos que representam os objetivos mais frequentes podem gerar tensões nos três níveis citados, tensões individuais ou coletivas, e muitas vezes articuladas:

- se a necessidade de reconhecimento é muito importante, as ansiedades identitárias e narcísicas podem se impor, inibindo e poluindo a produção coletiva. Inversamente, a afirmação de si ou do próprio ponto de vista pode ser insuficiente em razão dos riscos percebidos, como uma postura fóbica ou passivo-agressiva diante da dinâmica do grupo ou do narcisismo do outro;

- se a fertilidade afetiva, as necessidades de afiliação ou as tensões interpessoais tomam o lugar do objetivo operacional;

- se a estruturação ou a gestão do trabalho inibe a expressão livre e a criatividade;

- se as contribuições de alguns são aproveitadas por outros visando a interesses pessoais.

Tendo em conta tais elementos, apresentarei agora os processos psíquicos que me parecem os mais frequentes no interior dos grupos de trabalho.

1. Em primeiro lugar, a esperança e o prazer ligados à cooperação. Sem ir até o postulado de Pagès (1973) sobre um laço positivo imediato em todo grupo ou sobre um projeto autogestionário inconsciente, é preciso reconhecer o desejo constante de redução das tensões, de uma harmonia, de um sincronismo emocional (Avron, 1996), de uma convivialidade e do sucesso coletivo de um projeto, mesmo se tal expectativa (que nada tem de messiânico) se choca com as inevitáveis vicissitudes do trabalho em grupo e com os afetos por vezes ambivalentes que as acompanham. Nesse plano, sempre fiquei chocado com a fraca mobilização (sem falar das reações de inveja ligeiramente inconscientes) de certos analistas de grupo diante desses momentos de prazer, do sucesso do trabalho, como se tais momentos

\section{4}


fossem suspeitos, ao passo que reconhecê-los e explorá-los deveria ser digno de uma pulsão epistemofílica mais favorável.

2. Perturbações identitárias, que se devem à permanente confrontação de ideias, de posições e valores, inevitáveis em um trabalho verdadeiramente coletivo. Nesse ponto, a angústia de fragmentação (Anzieu, 1972) aparece e nos ronda, desde que associamos escuta empática e honestidade intelectual. É então que nos encontramos divididos, hesitantes, talvez até inconsistentes (atraídos, após algumas reflexões, por uma proposição que rejeitáramos anteriormente). Atribuição errônea de propósitos ou ações a alguns participantes, assim como "falsas" lembranças, atestam a confusão engendrada pelos debates no plano psíquico. Daí vêm as defesas, vividas desigualmente, contra uma espécie de provocação incômoda ao nosso núcleo psicótico, que podem tomar a forma de uma fechamento egocêntrico, de uma demanda grupal por uma estrutura mais rígida, por uma liderança mais firme.

3. Angústias de abandono despertadas pelos medos de desfiliação, de marginalização, desde que nos encontramos em posição minoritária ou que estranhas ressonâncias intersubjetivas levem o grupo a se proteger. Essa proteção pode tomar a forma do pensamento grupal (Janis, 1972), da ilusão grupal (Anzieu, 1971), do paradoxo de Abilene ${ }^{7}$ (Harvey, 1977), de cumplicidades e alianças defensivas (Kaes, 2009). Trata-se de processos grupais que têm em comum negar a complexidade, as hesitações, os desacordos.

4. O medo da ineficácia, da esterilidade, do vazio, geralmente atestado pela denúncia da "mania de reunião", fórmula "encobre tudo", e que remete, muitas vezes, ao desconhecimento dos fenômenos de grupo e às carências operatórias de uns e outros. Convém dizer que geralmente esse medo é permeado pelo prazer inconsciente de assistirmos a um fracasso (especialmente quando dependemos de uma gestão autoritária). A queixa comum que daí decorre permite facilmente a cada um eximir-se da própria responsabilidade no desenrolar do trabalho coletivo. Mas esse medo do "vazio" produz também movimentos depressivos, às vezes inesperadas passagens ao ato, individuais e/ou coletivas.

5. A ansiedade relativa ao status, vivida particularmente pelos responsáveis (Zaleznik, 1966). Ela pode manifestar-se a todo momento e também em qualquer membro do grupo. Assim, os grupos de trabalho são uma ocasião (muitas vezes dolorosa) de se descobrir que o próprio ponto de vista pode ter menos peso que o de outro colega cuja argumentação, longe de ser esclarecedora, é valorizada no centro dos debates em função de sua imagem, de sua aura ou do lugar que ele ocupa.

6. A superestimação da problemática do poder. Sem negar a existência de rivalidades (de pessoas, de pontos de vista etc.), as ansiedades paranoides são frequentemente exacerbadas, desde que apareçam divergências. O julgamento precoce de "manifestação de poder" atribuído a outrem pode referir-se a uma simples "veemência" (retomamos o termo de Winnicott), que talvez ateste o apego provisório à própria opinião. A confusão entre veemência e agressividade é frequente, mesmo que uma distinção clara entre essas duas expressões não seja evidente. A meu ver, a França é um dos países ocidentais em que a sensibilidade em relação aos fenômenos de poder (o que é comprovado por inúmeras publicações em ciências sociais) é a mais manifesta (Amado Faucheux \& Laurent, 1991), parcialmente em razão das tradições centralizadoras que estimulam a alternância entre dependência e contradependência (Crozier, 1970), bem mais que a interdependência.

7. A ambivalência em face da transgressão. Muitas vezes, ela ocorre nos grupos de trabalho, e tínhamos evocado sua necessidade para poder terminar o trabalho. Tudo se passa como se a prescrição fosse sentida de maneira superegoica, infiltrada inconscientemente por imagens parentais. Então, por culpabilidade (ou por estratégia, quando riscos diversos são claramente percebidos), vem um conformismo que impede a resolução criativa dos problemas

7 paradoxo de Abilene é o fenômeno de grupo em que todos os membros acabam por orientar-se em uma direção que, no fundo, nenhum deles desejava. 
abordados. Acrescentemos que a culpabilidade e um conformismo irrealista podem ser estimulados nos dispositivos estreitamente grupo-analíticos, desde que se observe, ou se estigmatize, uma distância em relação à prescrição, ou seja, à tarefa primeira.

8. A dialética "fantasia do absoluto/suficiente", isto é, a tensão entre o perfeccionismo (da análise, da realização) e o que é razoável, infiltrando-se nos debates de maneira mais ou menos explícita ante um problema específico. Quando muito, esse debate pode ser pertinente se considera as pressões do objetivo e os prazos, por exemplo. Mas, às vezes, ele é "pervertido" por situações de rigidez e por ansiedades que podem ser fruto de identidades ligadas a ofícios e/ou a problemáticas pessoais.

9. Enfim, nesse mesmo rumo, há duas modalidades defensivas, ligadas à organização do trabalho: a superestururação e a subestruturação da organização do trabalho (Amado, 1999). A superestruturação da organização do trabalho se manifesta pela centralização excessiva da liderança, pelo respeito escrupuloso à pauta do dia, por instruções, prazos, organização rigorosa de quem vai tomar a palavra, medo de derivas e do pensamento associativo. O pensamento operativo se imporia, então, à compreensão dos fenômenos de grupo, à tolerância da complexidade. No fundo, a superestruturação representaria uma proteção contra a conflitualidade e o emocional, uma luta contra o sempre temido caos pulsional, uma defesa contra as ansiedades psicóticas. Inversamente, a subestruturação da organização do trabalho tomaria a forma de uma abertura, uma tolerância e uma espécie de autogestão exacerbadas, respeitando pouco as pressões impostas pela realidade (do trabalho, da missão, da organização, dos prazos). As cumplicidades, os consensos, a exploração das tensões interpessoais visando à maior harmonia, a sensibilidade ao vivido emocional, tudo isso teria então um lugar central, em nome de uma ideologia igualitarista que nada parece poder fragilizar. Com efeito, essa subestruturação representaria uma defesa contra a influência, a competência e a diferenciação necessárias à realização da tarefa operacional. Essas duas modalidades defensivas - que poderíamos opor, como um superinvestimento do objeto-tarefa, de um lado, e um superinvestimento do objeto-grupo, de outro - na verdade são estreitamente ligadas. Elas constituem duas respostas extremas à inevitável tensão entre, de um lado, o desejo de ação, de realização, de eficácia e, de outro, a preservação da integridade psíquica, o respeito ao outro, o prazer de formar um grupo.

Compreende-se bem que há muita proximidade entre esses diversos fenômenos, que, de certa maneira, questionam a problemática identitária, buscada especialmente nos grupos de trabalho. Por isso, não nos parece inútil evocar as capacidades individuais potencialmente solicitadas, a fim de que os participantes, assim como o grupo, em conjunto, cheguem a uma realização criativa.

\section{Capacidades individuais para os grupos operacionais}

Como lembra Claudio Neri (2011, p. 33), "a participação no grupo de trabalho implica o desenvolvimento de certas capacidades que Freud havia indicado como características do eu do indivíduo: atenção, capacidade de representação verbal, capacidade de pensamento simbólico". No entanto, desde que se aceita a presença dos fenômenos acima descritos, as capacidades devem ser complementadas por algumas outras:

- em primeiro lugar, claro, uma competência (técnica, organizacional ou humana), relativa à tarefa a realizar. Tal evidência não salta sempre aos olhos, uma vez que as questões de status e de poder interferem nas condições ideais do trabalho de grupo. A presença inútil, por vezes suspeita, de hierarquias, o "olho de Moscou", ilustram tais dificuldades no interior das organizações; 
- a capacidade de empatia, que requer o "controle" da identificação projetiva e uma real congruência "daquele que escuta", sem o que a escuta aparentemente acolhedora pode transformarse em técnica de manipulação;

- a capacidade de transformação operativa (dos propósitos, das associações de ideias, dos afetos). Ela é um complemento importante para a simples empatia, desde que haja em vista um objetivo. Essa capacidade (que pode traduzir-se por formas como: "se eu sigo sua ideia, isso poderia nos conduzir a...”), desde que não utilizada de modo sistemático, representa uma espécie de antídoto contra os prazeres analíticos, dialéticos e linguageiros imoderados. Ela é próxima da capacidade, evocada por Lawrence, Bain e Gould (1996), de transformar as experiências;

- a capacidade de afirmação e de renúncia. Ligando essas duas noções, quero falar de um narcisismo de vida bem temperado, que implica, ao mesmo tempo, a individualização e a aceitação da castração simbólica que a honestidade intelectual deve nos ajudar a superar se aceitamos privilegiar o interesse coletivo. Defender o próprio ponto de vista é uma coisa, afirmá-lo "custe o que custar" é outra;

- a capacidade de superar a desestruturação, as angústias de fragmentação, a incerteza, tendo assim acesso à depressividade vital (Gammill, 2011), a única capaz de conter a complexidade psíquica e psicossocial e de conduzir à criatividade.

Tais capacidades são difíceis de se adquirir? A resposta de Bion é surpreendente: "A cooperação nos grupos de trabalho, assim como a participação, só seria possível em indivíduos com muitos anos de formação e com uma capacidade de experiência que lhes tenha permitido desenvolver-se mentalmente" (citado por French \& Simpson, 2010, p. 1865). Evidentemente, este não é nosso ponto de vista. A afirmação de Bion me parece ligada precisamente à sua concepção de grupos de trabalho. De fato, desde que uma atividade e um objetivo comum são partilhados, parece que em geral os participantes são capazes de se articular rapidamente e de maneira surpreendente, sem necessidade de experiências anteriores ou de uma formação qualquer que os predisponha a isso. Para compreender esse tipo de fenômeno no plano emocional e energético, as proposições de Ophélia Avron (2012) a respeito de uma "pulsão de interligação", de um processo primário de "emocionalidade participativa rítmica", parecem mais esclarecedoras. No plano do "real", somemos o fato de que a atividade partilhada tem um papel de mediação e, assim, oferece uma base de segurança, de forma a atenuar os sistemas defensivos. Afinal, é isso que se torna claro nos dispositivos de formação e de intervenção que compreenderam esse fenômeno.

\section{Formação e intervenção}

Se nos voltamos agora para a formação e a intervenção, é preciso reconhecer que, recolocando o trabalho no interior dos grupos, pode-se facilitar o seu desenvolvimento em diversos planos paralelos:

- do próprio conhecimento da práxis;

- dos desafios e dos impactos organizacionai ligados aos ofícios;

- da solidariedade profissional;

- do amadurecimento, nos planos psíquico e da cidadania.

Para nós, a maioria dos seminários de dinâmica de grupo visam sobretudo à última dimensão, apoiando-se unicamente no "aqui e agora" ligado a questões cuja relação com a vida profissional está longe de ser evidente. Falta, nesse ponto, a análise do contexto institucional, da natureza do trabalho e do papel desempenhado pelo dispositivo de formação utilizado. Daí vêm as inevitáveis desorientações psíquicas ou mesmo as descompensações "psicóticas", assim como o aparecimento de insights ambíguos sobre as relações interpessoais e certa fascinação pela 
esfera emocional, muito valorizada hoje - de maneira suspeita - pelos representantes da última moda psicológica: a inteligência emocional (Amado, 2008). Tais "derivas" podem ser evitadas, desde que o trabalho seja colocado no centro, se possível nos grupos de ofício.

No plano da formação, esse é o caso dos grupos de análise de práticas, quase sempre inspirados no trabalho pioneiro do psicanalista Michael Balint. Esses grupos, compostos por oito a doze médicos sob a "condução" de um psicanalista, buscavam elucidar um caso prático apresentado sem anotações, graças à procura em comum pelas origens de dificuldades. Seria por acaso que Balint excluía tudo que se refere à transferência privada do médico, mostrando-se sempre reservado em relação ao papel central do líder e da interpretação, facilitando, de preferência, a compreensão da "transferência pública" (transferências laterais)? Tentanto criar uma "companhia de investimento mútuo", mantendo o não saber como bases do questionamento, ele abriu um caminho fértil para a exploração dos desafios psíquicos do ofício, em especial aqueles em que a relação tem um papel essencial.

Convém ainda que os "animadores" de tais grupos disponham de uma familiaridade distanciada com os ofícios em questão. Sem tal capacidade, ao longo dos debates eles correm o risco de apenas focalizar as questões psicológicas individuais e coletivas em detrimento de suas ligações com a natureza do trabalho e com o contexto organizacional. É isso que busca evitar, por exemplo, a intervenção sociopsicanalítica de Gérard Mendel (Mendel, 1998; RueffEscoubès, 2008), centrada essencialmente no trabalho e na relação com o trabalho dos assariados, excluindo justamente o foco nas relações interpessoais e a exploração em profundidade da dinâmica dos grupos de ofício, que constituem a base da intervenção.

É interessante notar que os dois eminentes psicanalistas, Balint e Mendel, tenham escolhido, ao lado de sua prática "clássica" da cura, ajudar os profissionais (os médicos, para Balint, e as diferentes categorias de assalariados das organizações e instituições, para Mendel) a adquirir a clarividência e o poder sobre seu ato de trabalho cotidiano. Acrescente-se que, para realizar tal objetivo, os dois afastaram a transferência sobre a pessoa central do grupo, a fim de privilegiar a "simples" função de facilitadores das trocas em torno da prática, o que valeu a Balint a exclusão do Instituto Tavistock e a Mendel uma relativa marginalização na Sociedade Psicanalítica de Paris. Ora, foi o conhecimento dos processos inconscientes, de um lado, e dos riscos da análise fora do campo da cura, de outro, que os conduziu a uma prudente prática social. O sucesso de inumeráveis grupos Balint mundo afora (desde a criação da primeira sociedade Balint, na França, em 1967) e das inúmeras intervenções sociopsicanalíticas na Europa, na América do Sul e no Canadá testemunham a pertinência dos dispositivos propostos.

No entanto, os grupos de trabalho não se reduzem aos grupos de ofício homogêneos. Longe disso: os grupos de projetos plurifuncionais, as "forças-tarefa", as equipes virtuais internacionais (Chevrier, 2012), as equipes de pesquisa pluridisciplinar e, mais comumente, as equipes de trabalho no interior das organizações, possibilitam a exploração de sua dinâmica manifesta e inconsciente. Nessa direção, abre-se um campo bastante vasto. Explorar a relação entre uma atividade grupal específica ou os processos psíquicos que ela solicita no interior do coletivo de trabalho. Essa é a perspectiva que se destaca ao termo destas reflexões.

No plano dos grupos, a abordagem psicossociológica do trabalho poderia então ser aquela que, colocando a atividade no centro, tenta esclarecer as questões psíquicas em jogo (individuais e coletivas), assim como as questões éticas que a afetam, sempre levando em conta as pressões técnicas e oriundas do ambiente organizacional ou cultural, visando ao desabrochar das forças criadoras.

Ao enfatizar os dois objetivos, a análise e a criatividade, é preciso dizer que, sozinha, por mais pertinente que seja, a análise não garante um efeito de mudança e pode conduzir a certa condescendência intelectual, talvez mesmo ao aumento do sofrimento se este não estiver previsto no dispositivo de análise.

\section{8}


Além dessas considerações, parece, como dissemos, que o trabalho pode desempenhar o papel de mediação nos grupos de formação e/ou intervenção. Ora, como assinala Kaës (2004, p. 14), "a mediação permite que o sujeito explore o espaço interno, sem se perder nele, e o espaço comum partilhado". Afirmando a ausência de perigo ("sem se perder") nesses grupos com mediação, Kaës deixa claro o aspecto estruturante (defensivo, dizem alguns) do elemento mediador ou, em outras palavras, sua "função transicional" (Amado \& Ambrose, 2002; Amado \& Vansina, 2005). Em paralelo à análise e à realização da atividade, isso pode facilitar, um trabalho psíquico securizante. Com efeito, quando discutimos o trabalho, na verdade estamos falando de outra coisa, sobre a qual às vezes somos parcialmente ingênuos. No entanto, ao mesmo tempo, podemos compreender diversas coisas sobre nós mesmos, sobre os outros, sobre o modo como estamos presentes no mundo e sobre nossa ação sobre ele.

\section{Referências}

Amado, G. (1999). Groupes opérationnels et processus inconscients. Revue Française de Psychanalyse, 63 (3), 905. 916.

Amado, G. (2008). Emprise et dégagement dans les organisations et les relations de travail. Revue de Psychothérapie Psychanalytique de Groupe, 51 (2), 15-32.

Amado, G. \& Ambrose, A. (2001). The transitional approach to change. Londres/Nova York: Karnac Books.

Amado, G., Faucheux, C. \& Laurent, A. (1991). Organizational change and cultural realities: Franco-American contrasts. International Studies of Management and Organization, 21 (3), 62-95.

Amado, G. \& Guittet, A. (2012). Dynamique des communications dans les groupes. Paris: Armand Colin.

Amado, G. \& Lhuilier, D. (2012). L'activité au cœur de l'intervention psychosociologique. Bulletin de Psychologie, 65 (3), 263-276.

Amado, G. \& Vansina, L. (2005). The transitional approach in action, Londres/Nova York: Karnac Books.

Anzieu, D. (1971). L'illusion groupale. Nouvelle Revue de Psychanalyse, 4, 73-93.

Anzieu, D. et al. (1972). Le travail psychanalytique dans les groupes. Paris: Dunod.

Armstrong, D. (1992). Names, thoughts, and lies: the relevance of Bion's later writing for understanding experiences in groups. Free Associations, 3 (26), 261-282.

Avron, O. (2012). La pensée scénique. Toulouse: Érès.

Bejarano, A. (1973). Le leadership comme fonction de résistance et de transfert. In D. Anzieu et al. (Orgs.), Le travail psychanalytique dans les groupes (pp. 65-140, Coleção Inconscient et Culture). Paris: Dunod.

Bion, W. (1965). Recherches sur les petits groupes. Paris: PUF.

Brown, D. (1985). Bion and Foulkes: basic assumptions and beyond. In M. Pines (Org.), Bion and group psychotherapy. London: Routledge.

Chevrier, S. (2012). Peut-on faire virtuellement équipe? Le cas des equips internationales de projet. Nouvelle Revue de Psychosociologie, 14, 35-50.

Clot, Y. (2009). Travail et pouvoir d'agir. Paris: PUF.

Crozier, M. (1970). La société bloquée. Paris: Seuil.

Dejours, C. (2009). Travail vivant. Tome 2: travail et émancipation. Paris: PUF.

Dejours, C. (2012). Préface: La théorie sociale de Freud. In S. Freud, Psychologie des foules et analyse du moi (pp. 7 15). Paris: Payot.

Fabris, F. A. (2007). Pichon-Rivière, un viajero de mil mundos: génesis e irrupción de un pensamiento nuevo. Buenos Aires: Polemos.

Fabris, F. A. (2012). Pichon-Rivière y la construccion de lo social. Pasos y estrategias de una praxis colectiva. BuenosAires: Polemos.

French, R. B. \& Simpson, P. (2010). The work group: redressing the balance in Bion's experiences in groups. Human Relations, 63 (12), 1859-1878. 
Gammill, J. (2011). La position dépressive au service de la vie. Paris: In Press.

Grotstein, J. S. (2004). The seventh servant. The implications of a truth drive in Bion's theory of "O". International Journal of Psychoanalysis, 85 (5), 1081-1101.

Harrison, T. (2000). Bion, Rickman, Foulkes and the Northfields experiments. London: Jessica Kingsley.

Harvey, J. (1974). The Abilene paradox and other meditations on management. Toronto: Lexington.

Hinshelwood, R. D. (2008). Bion and Foulkes. Le groupe comme un tout. Revue de Psychothérapie Psychanalytique de Groupe, 52, 99-109.

Jaitin, R. (1994). Le porte-voix dans l'œuvre d'Enrique Pichon-Rivière. Revue de Psychothérapie Psychanalytique de Groupe, 23, 175-179.

Jaitin, R. (2002). Théories et méthodes de formation à l'école de Pichon-Rivière (Buenos-Aires). Revue Française de Psychothérapie Psychanalytique de Groupe, 2 (39), 141-179.

Kaës, R. (2004). Médiation, analyse transitionnelle et formations intermédiaires. In B. Chouvier (Org.), Les processus psychiques de la médiation (pp. 11-28). Paris: Dunod.

Kaës, R. (2009). Les alliances inconscientes. Paris: Dunod.

Lapassade, G. (1967). Groupes, organisations et institutions. Paris: Gauthier-Villars.

Lawrence, W. G., Bain, A. \& Gould, L. (1996). The fifth basic assumptions. Free Associations, 6 (1), 28-55.

Levy, A. (1972), Analyse critique du groupe d'évolution et ses développements récents. Connexions, 1, 13-42.

Lhuilier, D. (2006a). Le travail. In J. Barus-Michel, E. Enriquez \& A. Lévy (Orgs.), Vocabulaire de psychosociologie. Toulouse: Érès.

Lhuilier, D. (2006b). Cliniques du travail. Toulouse: Érès.

Malan, D. H., Balfour, F. H. G., Hood, V. G. \& Shooter, A. M. N. (1976). Group psychotherapy: a long-term follow-up study. The Archive of General Psychiatry, 33, 1303.

Mendel, G. (1998). L'acte est une aventure. Paris: La Découverte.

Menzies-Lyth, I. (2002). The life of Isabel Menzies-Lyth. An interview by Branca Pecotic. Organizational and Social Dynamics, 2 (1), 2-42.

Neri, C. (2011). Le groupe. Manuel de psychanalyse de groupe. Toulouse: Érès.

Nitsun, M. (1996). The anti-group. London/New York: Routledge.

Pagès, M. (1973). Inconscient collectif et changement social. Bulletin de Psychologie, 32, 929-940.

Pichon-Rivière, E. (2004). Le processus groupal. Toulouse: Érès.

Pines, M. (2009). L'influence de John Rickman et de Mélanie Klein sur W. R. Bion. Revue de Psychothérapie Psychanalytique de Groupe, 52, 7-18.

Rosenthal, R. \& Jacobson, L. (1971). Pygmalion à l'école. Paris: Casterman.

Rouchy, J. C. (1986). Une topique groupale. Revue de Psychothérapie Psychanalytique de Groupe, 5, 105-116.

Rueff-Escoubes, C. (2008). La sociopsychanalyse de Gérard Mendel. Paris: La Découverte.

Sher, M. (1988). From groups to groups relations: Bion's contribution to the Tavistock "Leceister" Conferences. In R. Lipgard \& M. Pines (Orgs.), Building on Bion: branches (pp. 109-144). London: International Library of Group Analysis.

Tubert-Oklander, J. \& Hernandez de Tubert, R. (2004). Operative groups, the Latin American approach to group analysis. London/New York: Jessica Kingsley.

Zaleznik, A. (1966). Human dilemmas of leadership. New York: Harper \& Row.

\section{Endereço para correspondência amado@hec.fr}

